\title{
Lung cancer in relation to exposure to silica dust, silicosis and uranium production in South African gold miners
}

\author{
Eva Hnizdo, Jill Murray, Sarah Klempman
}

\begin{abstract}
Background - A nested case-control study for lung cancer was performed on a cohort of 2260 South African gold miners in whom an association between exposure to silica dust and risk of lung cancer was previously reported. The objective was to investigate an expanded set of risk factors and also cancer cell type.

Methods - The 78 cases of lung cancer found during the follow up period from 1970 to 1986 were matched with 386 controls. Risk of lung cancer was related to smoking, exposure to silica dust, incidence of silicosis, and uranium production and the uranium content of the mine ore.

Results - The risk of lung cancer was associated with tobacco smoking, cumulative dust exposure, duration of underground mining, and with silicosis. The best predictive model included pack years of cigarette consumption (adjusted relative risk $(R R)=1.0$ for $<6.5$ pack years, 3.5 (95\% confidence interval (CI) 0.7 to 16.8) for 6.5-20 pack years, 5.7 (95\% CI 1.3 to 25.8 ) for 21-30 pack years, and 13.2 (95\% CI 3.1 to 56.2) for more than 30 pack years) and silicosis $(R R=2.45(95 \%$ CI 1.2 to 5.2$))$. No association was found with uranium production. The lung tumour cell type distribution was $40.3 \%$ small cell carcinoma, $38.8 \%$ squamous cell, $16.4 \%$ adenocarcinoma, and $4.5 \%$ large cell carcinoma. Small and large cell cancer combined were associated with exposure to dust.

Conclusions - The results cannot be interpreted definitively in terms of causal association. Possible interpretations are: (1) subjects with high dust exposure who develop silicosis are at increased risk of

conglomerates composed of a coarse fraction of waterworn pebbles set in a finer grained matrix. The rock is composed of quartz (70 $90 \%$ ), silicates $(10-30 \%)$, pyrite $(1-4 \%)$, and heavy minerals $(2-4 \%)$ which include grains of gold and uranium-bearing minerals. ${ }^{1}$

The levels of exposure to dust ${ }^{2}$ and $\alpha$ radiation ${ }^{34}$ and the risk of lung cancer in South African gold miners has been investigated in several epidemiological studies. A mortality study of 3971 white miners followed from 1970 for nine years ${ }^{5}$ reported a standardised mortality ratio (SMR) for lung cancer of 161 (95\% CI 116 to 220) and a relative risk (RR) of 1.8 (95\% CI 0.94 to 3.31 ), $p=0.06$, for one unit of 10000 particle years. A follow up period extended to 20 years resulted in an SMR of 139 (95\% CI 118 to 165 ) and RR of 1.08 (95\% CI 0.94 to 1.20$), \mathrm{p}=0.13 .^{6}$ Two casecontrol studies of lung cancer, in which cases and controls were ascertained from the Gold Miners Provident Fund ${ }^{7}$ and from necropsy records, ${ }^{8}$ respectively, found no association between exposure to silica dust or silicosis and lung cancer.

A second mortality study involved a cohort of 2260 white gold miners followed from 1970 to 1986 . In this study the association between death from lung cancer and cumulative dust exposure was statistically significant $(R R=$ $1.023,95 \%$ CI 1.005 to 1.042$).^{9}$

The objective of the present study was to conduct a nested case-control study of lung cancer in these 2260 miners and to examine an additional set of risk factors not previously studied, including radiological silicosis diagnosed using International Labour Organisation criteria and uranium mining. Occupational histories and dust exposure were re-coded in more detail. Cancer cell type was also examined.
\end{abstract} lung cancer; (2) high levels of exposure to silica dust on its own is important in the pathogenesis of lung cancer and silicosis is coincidental; and (3) high levels of silica dust exposure may be a surrogate for the exposure to radon daughters.

(Thorax 1997;52:271-275)

Keywords: silicosis, silica dust, exposure pattern, lung cancer, cell types.

Dr E Hnizdo, Epidemiology

Section, National Centre for

Occupational Health,

P O Box 4788 ,

Johannesburg 2000, South

Africa.

Received 23 April 1996

Returned to authors

15 July 1996

Revised version received

7 October 1996

Accepted for publication

30 October 1996

\section{Methods}

STUDY DESIGN

Details of the original mortality study have been reported previously. ${ }^{9}$ The cohort of 2260 were all white gold miners who attended medical examination during 1968-1972, were 45-54 years of age, and had spent at least 10 years working in gold mines with minimal exposure to other types of mines. Subjects were followed up to 31 December 1986.

There were 78 cases of lung cancer (ICD-9, The South African gold mining industry employs a labour force of several hundred thousand miners. Most gold mining is done on the Witwatersrand reefs at depths of up to $3500 \mathrm{~m}$. Geologically, the reefs consist of quartz-pebble
162), of which 69 had a necropsy at the National Centre for Occupational Health $(\mathrm{NCOH})$ and nine had lung cancer mentioned as a cause of death on the death certificate. 
The cases were each matched to a set of five controls, selected from the cohort of 2260 miners, and matched on the year of birth and survival of the case. ${ }^{10}$

\section{NECROPSY EXAMINATION}

In total, $85 \%$ of the cohort members who died had a necropsy at the $\mathrm{NCOH}$ where the presence and degree of silicosis are determined for compensation purposes. ${ }^{11}$ Two pathologists (JM and SK) performed the cell typing independently and blindly on 67 cases with primary lung tumours using the 1982 World Health Organisation guidelines.

\section{CALCULATION OF DUST EXPOSURE}

The occupational histories were coded from the original Chamber of Mines personal exposure records which show the number of shifts worked in a particular mine and the occupation during a given period for the entire career of each miner. Occupations were grouped into nine categories and assigned average dust levels and the average time spent underground as estimated in the late $1960 \mathrm{~s}^{2}$ The dust levels were calculated in terms of $\mathrm{mg} / \mathrm{m}^{3} .^{12}$

Two measures of dust exposure were calculated: (1) cumulative dust exposure (CDE) in $\mathrm{mg} / \mathrm{m}^{3}$-years, calculated as $\Sigma$ (number of dusty shifts $\times$ mean mass respirable dust concentration (table $1^{13}$ ) $\times$ average number of hours spent underground (table $\left.\left.1^{13}\right)\right) /(270 \times 8)$; and (2) the net number of years spent in dusty occupations underground (YEARS), calculated as $\Sigma$ (number of dusty shifts $\times$ average numbers of hours spent underground by the occupational category) $/(270 \times 8)$. The summation is for all jobs in which a miner worked, and 270 is the average number of shifts per year multiplied by eight to obtain eight hour standardised years. This method of calculation was first used by Beadle ${ }^{14}$ to estimate the risk of silicosis and displayed a strong dose-response relationship with silicosis in this cohort also. ${ }^{13}$

CDE and YEARS were lagged by $0,5,10$, and 20 years from the death of the case and related to the risk of lung cancer.

\section{URANIUM PRODUCTION}

Only sporadic measurements of radon daughters have been made on the gold mines and these were not available to us. The yearly uranium production in each mine was obtained from published tabulated data. ${ }^{1}$ The average

Table 1 Mean (SD) characteristics of the cases and controls in relation to mortality and radiological follow up

\begin{tabular}{llllll}
\hline Follow up events & \multicolumn{2}{l}{ Lung cancer $(n=78)$} & & \multicolumn{2}{l}{ Controls $(n=386)$} \\
\cline { 2 - 3 } & Year & Age & & Year & Age \\
\hline Birth & $1918.8(2.6)$ & & & $1918.6(2.5)$ & \\
Silicosis onset (SILICOSIS)* & $1972.2(4.5)$ & $54.1(5.8)$ & & $1971.0(5.6)$ & $52.9(5.9)$ \\
Last exposure to dust & $1973.6(6.3)$ & $55.1(6.1)$ & & $1976.1(5.9)$ & $57.6(5.5)$ \\
$\begin{array}{l}\text { Most recent radiograph in } \\
\quad \text { non-silicotics }\end{array}$ & $1975.6(6.0)$ & $56.9(5.9)$ & & $1981.7(6.4)$ & $63.0(6.1)$ \\
Death/end of follow up & $1980.0(4.7)$ & $61.6(4.9)$ & & $1985.1(2.6)$ & $66.5(3.1)$ \\
\hline
\end{tabular}

* Silicosis onset applies to 15 of the lung cancer cases and 34 of the controls who had silicosis. Seven $(9.0 \%)$ of the cases and $41(10.6 \%)$ of the controls were lost to radiological follow up. grade of uranium in the ore $(\mathrm{kg} / \mathrm{metric}$ tonnes treated) was obtained from a table produced by the Chamber of Mines. ${ }^{15}$ Several indices were created using the same formula as for YEARS and CDE, but adding the total uranium production of the mine or the uranium grade of the ore in the mine as weighting factors.

\section{RADIOLOGICAL SILICOSIS}

While employed, the miners have annual radiological examinations and after retirement examinations continue, but less frequently. The radiographs of the 2260 miners were read by two experienced readers in chronological order, starting with the most recent, to determine the presence of silicosis (ILO category $1 / 1$ or higher) and the year of onset of silicosis (when category $1 / 1$ was first visible radiologically). ${ }^{11}$ The findings of the reader whose reading correlated most highly with the pathological findings were used. ${ }^{11}$

The year of death of the case lagged by three years determined the cut-off year for onset of silicosis (yes/no) (SILICOSIS) within each matched case-control risk set. The lagging by three years was done to prevent a bias due to changes on the radiographs associated with lung cancer. In addition, all miners (cases and controls) whose last radiograph was taken more than five years before the lagged three years were considered lost to the radiological follow up with the exception of miners who had no silicosis diagnosed at necropsy. This was justified as the specificity of the reader was 0.99 . The exclusion was done because silicosis is a progressive disease and could have developed during the five year interval. Exclusion of the subjects lost to radiological follow up did not significantly change the results.

\section{TOBACCO SMOKING}

The smoking habits of the 2260 miners were ascertained by a questionnaire in the 1968-72

Table 2 Characteristics of the subjects with lung cancer and controls

\begin{tabular}{|c|c|c|}
\hline Characteristic & $\begin{array}{l}\text { Cases } \\
(n=78)\end{array}$ & $\begin{array}{l}\text { Controls } \\
(n=386)\end{array}$ \\
\hline \multicolumn{3}{|c|}{$\begin{array}{l}\text { CDE20 (mg/m³-years) } \\
\text { quartiles }\end{array}$} \\
\hline$<2.7$ & $12(15.4)$ & $100(25.9)$ \\
\hline $2.7-4.3$ & $19(24.4)$ & $98(25.4)$ \\
\hline $4.4-6.3$ & $21(26.9)$ & $99(25.7)$ \\
\hline$>6.3$ & $26(33.3)$ & $89(23.1)$ \\
\hline \multicolumn{3}{|l|}{ YEARS20 } \\
\hline$<10$ & $9(11.5)$ & $68(17.6)$ \\
\hline $10-14$ & $25(32.1)$ & $133(34.5)$ \\
\hline $15-20$ & $23(29.5)$ & $113(29.3)$ \\
\hline$>20$ & $21(26.9)$ & $72(18.7)$ \\
\hline \multicolumn{3}{|c|}{$\begin{array}{l}\text { Cigarette consumption } \\
\text { (pack years in 1970) }\end{array}$} \\
\hline$<6.5$ & $3(3.9)$ & $85(22.0)$ \\
\hline $6.5-20$ & $10(12.8)$ & $85(22.0)$ \\
\hline $21-30$ & $19(24.4)$ & $97(25.1)$ \\
\hline$>30$ & $46(59.0)$ & $119(30.8)$ \\
\hline SILICOSIS present & $15(21.1)^{\mathrm{a}}$ & $34(9.9)^{\mathrm{b}}$ \\
\hline \multicolumn{3}{|c|}{$\begin{array}{l}\text { CDE20 = cumulative dust exposure lagged by } 20 \text { years from } \\
\text { death; YEARS } 20=\text { net number of years spent in dusty } \\
\text { occupations underground lagged by } 20 \text { years from death; } \\
\text { SILICOSIS = silicosis diagnosed up to three years before death } \\
\text { of a matched case. } \\
\text { a } 21.1 \% \text { out of } 71 \text {; seven subjects were lost to radiological follow } \\
\text { up. }\end{array}$} \\
\hline
\end{tabular}


Table 3 Relative risk (95\% confidence interval) for lung cancer estimated from the conditional logistic regression models and the goodness of fit statistic (-2 log likelihood)

\begin{tabular}{|c|c|c|c|c|c|}
\hline \multirow[t]{2}{*}{ Risk factor } & \multicolumn{5}{|c|}{ Logistic regression models } \\
\hline & Model $1(n=464)$ & Model $2(n=416)^{a}$ & Model $3(n=464)$ & Model $4(n=416)^{a}$ & Model $5(n=416)^{a}$ \\
\hline \multicolumn{6}{|c|}{ Cigarette consumption (pack years) } \\
\hline $6.5-20$ & $2.9(0.8$ to 11.0$)$ & $3.2(0.7$ to 15.6$)$ & $3.1(0.8$ to 11.7$)$ & $3.3(0.7$ to 16.2$)$ & $3.5(0.7$ to 16.8$)$ \\
\hline $21-30$ & $4.9(1.4$ to 17.0$)$ & $5.6(1.2$ to 25.0$)$ & $4.9(1.4$ to 17.0$)$ & $5.4(1.2$ to 24.2$)$ & $5.7(1.3$ to 25.8$)$ \\
\hline$>30$ & 10.1 (3.1 to 33.6$)$ & $13.3(3.1$ to 56.6$)$ & $10.1(3.0$ to 33.5$)$ & 12.7 (3.0 to 54.1$)$ & $13.2(3.1$ to 56.2$)$ \\
\hline \multicolumn{6}{|c|}{ CDE20 (mg/m³ -years) } \\
\hline $2.7-4.3$ & $1.83(0.8$ to 4.1$)$ & $1.78(0.8$ to 4.1$)$ & & & \\
\hline $4.4-6.3$ & $1.85(0.8$ to 4.3$)$ & $1.29(0.5$ to 3.2$)$ & & & \\
\hline$>6.3$ & $3.19(1.3$ to 7.6$)$ & $1.93(0.8$ to 5.0$)$ & & & \\
\hline \multicolumn{6}{|l|}{ YEARS20 } \\
\hline $10-15$ & & & $1.63(0.6$ to 4.6$)$ & $1.61(0.6$ to 4.5$)$ & \\
\hline $16-20$ & & & $2.07(0.7$ to 6.3$)$ & $1.53(0.5$ to 4.8$)$ & \\
\hline$>20$ & & & $3.36(1.02$ to 10.7$)$ & $1.59(0.5$ to 5.5$)$ & \\
\hline SILICOSIS & & $2.10(1.0$ to 4.6$)$ & & $2.35(1.1$ to 5.1$)$ & $2.45(1.2$ to 5.2$)$ \\
\hline-2 log likelihood & $240.5(\mathrm{df}=6)$ & $179.9(\mathrm{df}=7)$ & $242.8(\mathrm{df}=6)$ & $180.8(\mathrm{df}=7)$ & $182.2(\mathrm{df}=4)$ \\
\hline
\end{tabular}

CDE20 = cummulative dust exposure lagged by 20 years from death; YEARS20 = net number of years spent in dusty occupations underground lagged by 20 years

from death; SILICOSIS = silicosis diagnosed up to three years before death of a matched case.
${ }^{a}$ Forty eight subjects lost to radiological follow up were not included in models 2,4 , and 5.

medical examination and checked against tobacco consumption recorded during annual examinations in the medical files. Cigarette equivalent pack years for total tobacco and for cigarettes only were calculated. ${ }^{9}$

\section{STATISTICAL ANALYSIS}

$\mathrm{SAS}^{16}$ program PHREG for matched case-control analysis was applied to perform the conditional logistic regression and to estimate the relative risk. Dummy (0/1) variables were used to estimate the trend in odds ratios.

\section{Results}

Table 1 shows the year and age at various follow up events for the cases and controls, and table 2 shows the exposure characteristics of the cases and controls.

Table 3 shows the adjusted RR and 95\% confidence intervals for lung cancer estimated from models using different sets of risk factors, and the associated goodness of fit statistic $(-2$

Table 4 Mean (SD) for cumulative dust exposure (CDE), years of exposure (years), and smoking pack-years, according to the presence of silicosis and lung cancer

\begin{tabular}{|c|c|c|c|c|}
\hline \multirow[t]{2}{*}{ Variable } & \multicolumn{2}{|c|}{ Silicosis present } & \multicolumn{2}{|c|}{ Silicosis absent } \\
\hline & Cancer & Controls & Cancer & Controls \\
\hline $\begin{array}{l}\text { No. of miners* } \\
\mathrm{CDE}\left(\mathrm{mg} / \mathrm{m}^{3} \text {-years }\right)\end{array}$ & $15(19.2 \%)$ & $34(8.8 \%)$ & $56(71.8 \%)$ & $311(80.6 \%)$ \\
\hline $\begin{array}{l}\text { lagged } 0 \text { years } \\
\text { lagged } 10 \text { years } \\
\text { lagged } 20 \text { years }\end{array}$ & $\begin{aligned} 12.0(3.3) \dagger \\
10.7(3.0) \dagger \\
7.4(2.1) \dagger\end{aligned}$ & $\begin{array}{l}9.8(3.0) \\
8.7(2.4) \\
6.2(2.0)\end{array}$ & $\begin{array}{l}7.4(3.2) \\
6.3(2.7) \\
4.3(2.1)\end{array}$ & $\begin{array}{l}7.5(3.2) \\
6.4(2.9) \\
4.4(2.2)\end{array}$ \\
\hline YEARS & & & & \\
\hline $\begin{array}{l}\text { lagged } 0 \text { years } \\
\text { lagged } 10 \text { years } \\
\text { lagged } 20 \text { vears }\end{array}$ & $\begin{array}{l}31.5(6.6) \\
27.4(5.8) \\
19.4(4.7)\end{array}$ & $\begin{array}{l}28.5(6.1) \\
25.5(5.2) \\
180(4.5)\end{array}$ & $\begin{array}{l}25.1(6.8) \\
21.3(6.0) \\
14.7(5.1)\end{array}$ & $\begin{array}{l}25.1(6.7) \\
21.3(6.3) \\
14.6(5.2)\end{array}$ \\
\hline $\begin{array}{l}\text { lagged } 20 \text { years } \\
\text { Cigarette consumption } \\
\text { (pack years) }\end{array}$ & $36.1(18.7)$ & $21.8(14.6)$ & $37.7(18.3)$ & $23.0(17.8)$ \\
\hline
\end{tabular}

* Seven cases of lung cancer and 41 controls were lost to radiological follow up. $t \mathrm{p}<0.05$ cases versus controls with silicosis present.

Table 5 Distribution of cases and controls according to the presence of silicosis and categories of smoking, and the relative risks (RR)

\begin{tabular}{llcrr}
\hline Silicosis & $\begin{array}{l}\text { Cigarette consumption } \\
\text { (pack years) }\end{array}$ & $\begin{array}{l}\text { No. (\%) } \\
\text { of cases }\end{array}$ & $\begin{array}{l}\text { No. (\%) } \\
\text { of controls }\end{array}$ & RR(95\% CI) \\
\hline Absent & $<10$ & $2(2.8)$ & $83(24.1)$ & 1.0 \\
& $10-29$ & $20(28.2)$ & $130(37.7)$ & $5.1(1.2$ to 22.4$)$ \\
Present & $30+$ & $34(47.9)$ & $98(28.4)$ & $11.7(2.7$ to 49.8$)$ \\
& 10 & $1(1.4)$ & $8(2.3)$ & $4.1(0.3$ to 52.3$)$ \\
Total & $10-29$ & $4(5.6)$ & $18(5.2)$ & $7.9(1.4$ to 46.4$)$ \\
& $30+$ & $10(14.1)$ & $8(2.3)$ & $48.9(8.5$ to 281.4$)$ \\
\hline
\end{tabular}

$\log$ likelihood). Of the exposure variables, $\mathrm{CDE}$ and YEARS lagged by 20 years were most strongly associated with risk of lung cancer (models 1 and 3). When SILICOSIS was included in the model neither CDE nor YEARS showed a significant trend (models 2 and 4). The likelihood ratio statistic, $\chi^{2}$ MLR, comparing models 2 and $5\left(\chi^{2}\right.$ MLR $\left.=2.3, \mathrm{df}=3\right)$ and models 3 and $5\left(\chi^{2}\right.$ MLR $\left.=1.4, \mathrm{df}=3\right)$, were not statistically significant, indicating that when SILICOSIS was included in the model, CDE and YEARS did not contribute significantly to predicting the risk of lung cancer. Variables representing uranium mining were not significantly related to the risk of lung cancer and are thus not included in the table.

Table 4 shows the mean CDE and YEARS lagged by 0,10 , and 20 years, and pack years of cigarette consumption according to the presence of silicosis and lung cancer. Subjects with silicosis and lung cancer had the highest CDE and YEARS lagged by different years compared with the other groups. Those with cancer who were lost to radiological follow up had higher levels of dust exposure than the comparable controls, suggesting that the exclusion did not bias the result positively.

Table 5 shows the distribution of cases and controls according to the presence of silicosis and cigarette smoking, and the relative risks estimated from the matched analysis.

The lung tumour cell type was established for 67 of the 78 cases. The distribution of cell types was $40.3 \%$ for small cell carcinoma, $38.8 \%$ for squamous cell carcinoma, $16.4 \%$ for adenocarcinoma, and $4.5 \%$ for large cell carcinoma.

The smoking adjusted odds ratios for quartiles of CDE for small and large cell carcinoma combined were, respectively, 1.0, 2.8 (95\% CI 0.59 to 13.1 ), 4.9 (95\% CI 1.01 to 23.8 ), 6.0 (95\% CI 1.11 to 33.5 ) for CDE lagged by 20 years, and $1.0,1.6(95 \%$ CI 0.32 to 7.72$), 3.7$ (95\% CI 0.87 to 15.6 ), and 3.5 (95\% CI 0.77 to 15.9 ) for $\mathrm{CDE}$ lagged by 0 years.

\section{Discussion}

Tobacco smoking was the most significant predictor of lung cancer (table 3). Of the occupational exposure variables, CDE and 
YEARS - both lagged by 20 years from the death of the case - were the most significant predictors and showed a dose-response trend (table 3, models 1 and 3).

When silicosis (SILICOSIS) was included in the logistic model, together with CDE or YEARS, then only SILICOSIS and smoking remained statistically significant (table 3 , models 2, 4, and 5), suggesting that silicosis may be more important than exposure to dust. However, the relationship between CDE, SILICOSIS, and lung cancer is complex. Table 4 shows that cases of lung cancer with silicosis had significantly higher CDE and YEARS than controls with silicosis; this difference was not present in those without silicosis, suggesting that $\mathrm{CDE}$ is not a risk factor for lung cancer in these individuals. Tobacco smoking (pack years) was not a significant predictor for the risk of silicosis $(\mathrm{OR}=1.00, \mathrm{p}=0.40)$ or the age at onset of silicosis in the 351 cases of silicosis identified from the 2260 miners when adjusted for exposure to dust and year of birth.

The lack of association with variables representing uranium production and the uranium grade of the ore may be due to the fact that the ventilation rate, the most important determinant of $\alpha$-radiation in the mines, could not be taken into account. However, since most of the deep mines had low radiation levels, more precise measurements of $\alpha$-radiation would be required to detect an effect.

The data show a strong multiplicative combined effect of smoking and the presence of silicosis on the risk of lung cancer (table 5). For subjects in both the highest and lowest categories of daily cigarette consumption, the estimated RR for lung cancer was approximately four times higher in those with silicosis than in those who did not have silicosis. A similar combined effect was seen for smoking and cumulative silica dust exposure on the risk of lung cancer; this effect was described in detail in the mortality study. ${ }^{9}$

Interpretation of the results in terms of causal association is problematic, especially since CDE, YEARS, and SILICOSIS are highly correlated variables. Three possible causal relations can be suggested on the basis of the above results: (1) high silica dust exposure together with silicosis is required to increase the risk of lung cancer and subjects who are susceptible to developing silicosis are also at increased risk of developing lung cancer; (2) high silica dust exposure, mainly in heavy smokers, increases the risk of lung cancer and silicosis is incidental in the process; and (3) the risk is increased in miners who spend the longest hours underground in high levels of dust and the increased risk results from exposure to radon.

The frequency distribution of the cell types in the 67 miners who had a necropsy was in agreement with that obtained for another set of gold miners who had a necropsy during 1976-8 and were studied for cell type distribution. ${ }^{17}$ The cases in our study died between 1970 and 1986. In general, those with small cell and large cell carcinoma had greater ex- posure to respirable silica dust ( $\mathrm{mg} / \mathrm{m}^{3}$-years) than the matched controls.

The question remains as to why the two previous case control studies ${ }^{78}$ did not detect an association with silicosis or dust exposure. A critical assessment of potential biases in these two studies is necessary. In the first study ${ }^{7}$ the cases and controls were identified from deaths reported to the Gold Miners Provident Fund during 1979-83. Two controls were matched to each case by year of birth and cigarette consumption 10 years prior to death. Radiographs taken at least three years before death were read for the presence of silicosis. There are two possible sources of bias: (1) because of the way a miner's death is reported to the Fund, deaths of miners with more than 15 years of service were more likely to be reported than those with shorter service so overmatching for dust exposure may have occurred; (2) controls were matched to cases of lung cancer for smoking and effectively for death also. Cases of lung cancer have high levels of cigarette consumption and die prematurely, but it is very likely that the controls also died prematurely due to smoking related diseases such as chronic obstructive pulmonary disease, cardiovascular diseases, and others. CDE and smoking are risk factors for early death from all causes in gold miners ${ }^{18}$ so matching for smoking and death may have led to overmatching for dust exposure and silicosis.

Participants in the second study ${ }^{8}$ were selected from all miners who had a necropsy at the $\mathrm{NCOH}$ between 1974 and 1986. The cases and controls were stratified by age at death but, because the year of birth was not controlled for, cases of the same age at death who were born at different time periods and hence also worked at different times were compared. Thus, miners whose exposure was prior to the 1930s, when dust levels were very high, were assigned the same weighting factor for the same occupational category as those whose exposure was after the 1930s when dust levels were dramatically reduced, and were compared in the matched analysis. In addition, a significantly lower percentage of miners who are awarded the highest degree of compensation in life have a necropsy ( $65 \%$ versus $85 \%$ ). This applies, in particular, to miners with silicosis who are heavy smokers, since miners with pneumoconiosis who have COPD in life are awarded the highest compensation.

The findings from different studies on the association between lung cancer, exposure to silica dust, and silicosis in South African gold miners differ, and therefore this study should not be considered conclusive. Nevertheless, the finding that a high level of exposure to silica dust early in life and a susceptibility to develop silicosis are associated with increased risk of lung cancer, and that exposure to silica dust/ silicosis acts synergistically with smoking on the risk of lung cancer, concurs with a recent review. ${ }^{19}$

The authors are grateful to Colleen Summerson from the Epidemiology Research Unit at the Medical Bureau for Occupational Diseases for her diligent coding of work histories, 
and thank the pathologists from $\mathrm{NCOH}$ who performed the necropsies.

1 Ford MA. Uranium in South Africa. $\mathcal{F} S$ Afr Inst Mining Metall 1993;93:37-58.

2 Page-Shipp RJ, Harris E. A study of the dust exposure of South African white gold miners. If S Afr Inst Mining Metall 1972;73:10-24.

3 Greig JD, Rolle R, Dods VB, Hampson BG, et al. Report on survey of radon and radon-daughter concentration in twenty-five gold mines 1969/70. Johannesburg: Chamber of Mines of South Africa Report No. 36/70, 1970.

4 Wyndham CH, Heyns AJA, Keeley WH, Barnard CPS. Lung cancer death rates among white South African gold miners. Johannesburg: Chamber of Mines of South Africa Report No. 23/70, 1970

5 Wyndham CH, Bezuidenhout BN, Greenacre MJ. Mortality of middle aged white South African gold miners. $\mathrm{Br} F$ Ind Med 1986;43:677-84

6 Reid PJ, Sluis-Cremer GK. Mortality of South African gold miners. Occup Environ Med 1996;53:11-16.

7 Hessel PA, Sluis-Cremer GK, Hnizdo E. Case-control study of silicosis, silica exposure, and lung cancer in white South African gold miners. Am f Ind Med 1986;10:57-62.

8 Hessel PA, Sluis-Cremer GK, Hnizdo E. Silica exposure, silicosis, and lung cancer: a necropsy study. Br f Ind Med 1990;47:4-9.

9 Hnizdo E, Sluis-Cremer GK. Silica exposure, silicosis, and lung cancer: a mortality study of South African gold miners. Br f Ind Med 1991;48:53-60.
10 Liddell FDK, McDonald JC, Thomas DC. Methods of cohort analysis: appraisal by application to asbestos mining. F R Stat Soc $(A)$ 1977;140:469-91

11 Hnizdo E, Murray J, Sluis-Cremer GK, Glyn-Thomas R. Correlation between radiological and pathological diag nosis of silicosis: an autopsy population based study. $A m$ F Ind Med 1993; 24:427-445.

12 du Toit RSJ. The shift mean respirable mass concentration of eleven occupations of Witwatersrand gold miners. Johannesburg: NCOH Report 4/91, 1991.

13 Hnizdo E, Sluis-Cremer GK. Risk of silicosis in a cohort of white South African gold miners. Am f Ind Med 1993; 24:447-57.

14 Beadle DG. The relationship between the amount of dust breathed and the development of radiological signs of silicosis: an epidemiological study of South African gold miners. In: Walton WH, ed. Inhaled particles III. Oxford: Pergamon Press, 1971:951-64.

15 Uranium ore grade in South African gold mines. Johannesburg: Chamber of Mines of South Africa Report, 1991 .

16 SAS Institute Inc. SAS/STAT user's guide. Release 6.03 Edition. Cary, NC: SAS Institute Inc, 1988.

17 Klempman S. Primary malignant lung tumours in South African gold miners: a study of cell type distribution. PhD Thesis, Johannesburg, 1986 .

18 Hnizdo E. Health risk among white South African gold miners: dust, smoking and chronic obstructive pulmonary miners: dust, smoking and chronic obstr

19 Weill H, McDonald JC. Exposure to crystalline silica and risk of lung cancer: the epidemiological evidence. Thorax 1996;51:97-102. 